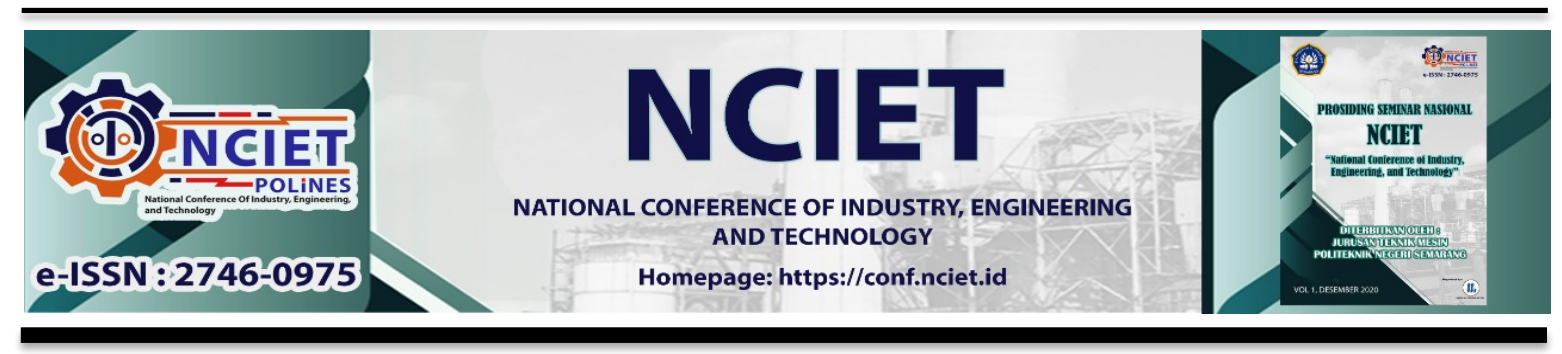

Prosiding Seminar Nasional NCIET Vol.1 (2020) B162-B169

$1^{\text {st }}$ National Conference of Industry, Engineering and Technology 2020,

Semarang, Indonesia.

\title{
PERBANDINGAN BIAYA PERANCANGAN PLTS ON-GRID DAN OFF-GRID PADA LABORATORIUM LISTRIK PPSDM MIGAS
}

\author{
Rahmat Jalaluddin*, Yanuar Mahfudz S. \\ Jurusan Teknik Mesin, Politeknik Negeri Semarang \\ J1. Prof. H. Soedarto, S.H., Tembalang, Semarang, 50275 \\ *E-mail: rhmtjllddn@gmail.com
}

\begin{abstract}
Abstrak
Energi surya selain mudah didapatkan di alam, juga ramah lingkungan yaitu tidak memiliki emisi $\mathrm{CO}^{2}$ sehingga menjadi teknologi alternatif andalan. Selain itu teknologi surya telah dirancang mudah dalam instalasi, operasi, dan perawatan. Namun kekurangannya adalah teknologi surya ini membutuhkan investasi awal yang lebih mahal dibandingkan teknologi pembangkit konvensioanl lain-nya seperti PLTD yang menggunakan diesel sebagai prime mover dan generator sebagai penghasil energi listrik, tetapi untuk pemakaian jangka panjang penggunaan teknologi surya patut diperhitungkan dalam penggunaan on-grid maupun off-grid. Oleh sebab itu, dilakukanlah sebuah perancangan PLTS pada Lab. Listrik pada PPSDM MIGAS Cepu dengan menggunakan sistem on-grid dan off-grid. Sehingga dapat diketahui tingkat efisiensi dalam segi biaya pembuatan PLTS on-grid, PLTS off-grid, atau listrik PLN penuh pada Lab. Listrik dalam kurun waktu operasi 25 tahun. Dari hasil perancangan tersebut didapatkan bahwa pembuatan PLTS on-grid memiliki tingkat biaya yang lebih rendah dibandingkan PLTS off-grid dan listrik PLN penuh. Akan tetapi dalam pelaksanaannya PLTS on-grid masih menggunakan listrik PLN saat langit mendung atau malam hari. Sedangkan pada PLTS off-grid membutuhkan biaya yang cukup banyak, dikarenakan pada sistem ini menggunakan baterai sebagai penyimpan listrik. Dimana baterai tersebut memiliki harga yang cukup mahal, serta dalam kurun waktu 5 tahun harus dilakukan pergantian.
\end{abstract}

Kata Kunci: Sel Surya; Panel Surya On-Grid; Panel Surya Off-Grid; Listrik PLN; EBT

\section{PENDAHULUAN}

Indonesia memiliki kekayaan Minyak dan Gas Bumi (Migas) yang melimpah. Tetapi tetap harus dilakukan penanganan serta pemberdayaan kedua sumber daya alam tersebut agar dapat dimanfaatkan sebaik mungkin oleh manusia. Sehingga, dalam penanganannya negara Indonesia memiliki beberapa lembaga yang menangani sumber daya minyak dan gas bumi, salah satunya adalah Pusat Pengembangan Sumber Daya Manusia Minyak dan Gas Bumi (PPSDM MIGAS) yang berada dibawah naungan Kementerian Energi dan Sumber Daya Mineral (Kementerian ESDM).

Fungsi atau Tugas pokok dari PPSDM MIGAS Cepu sendiri antara lain 
menyelenggarakan pelatihan, sertifikasi, jasa teknologi, dan jasa keahlian. Selain sebagai lembaga yang menyelenggarakan pendidikan serta pelatihan, PPSDM MIGAS Cepu juga ikut serta mengolah minyak dan gas menjadi bahan bakar seperti solar, kerosin, pertasol, dan lilin.

Dengan adanya berbagai kegiatan dan aktivitas yang ada di lingkungan PPSDM MIGAS Cepu, maka diperlukan pasokan listrik yang menunjang segala aktivitas demi keberlangsungan kegiatan. PPSDM MIGAS Cepu mempunyai unit kepembangkitan tenaga listrik sendiri yang menggunakan Mesin Diesel (PLTD). Sedangkan kita tahu bahwa ketersediaan Migas di alam semakin lama semakin berkurang. Oleh sebab itu perlu dilakukan perancangan pembuatan Pembangkit Listrik Tenaga Alternatif yaitu Pembangkit Listrik Tenaga Surya (PLTS) pada salah satu tempat di PPSDM MIGAS Cepu untuk mengurangi penggunaan Sumber Daya Alam (SDA) MIGAS yang semakin lama semakin berkurang keberadaannya. Tetapi dalam pelaksanaannya, PLTS memiliki biaya pengadaan yang lebih besar daripada energi konvensional lain. Maka kali ini dilakukanlah perbandingan perancangan Pembangkit Listrik Tenaga Surya On-Grid dan Off-Grid, serta harga listrik PLN yang terpakai pada Lab.Listrik PPSDM Migas. Sehingga dapat ditemukan perancangan dengan efisiensi terbaik dalam segi biaya.

\section{METODE PENELITIAN}

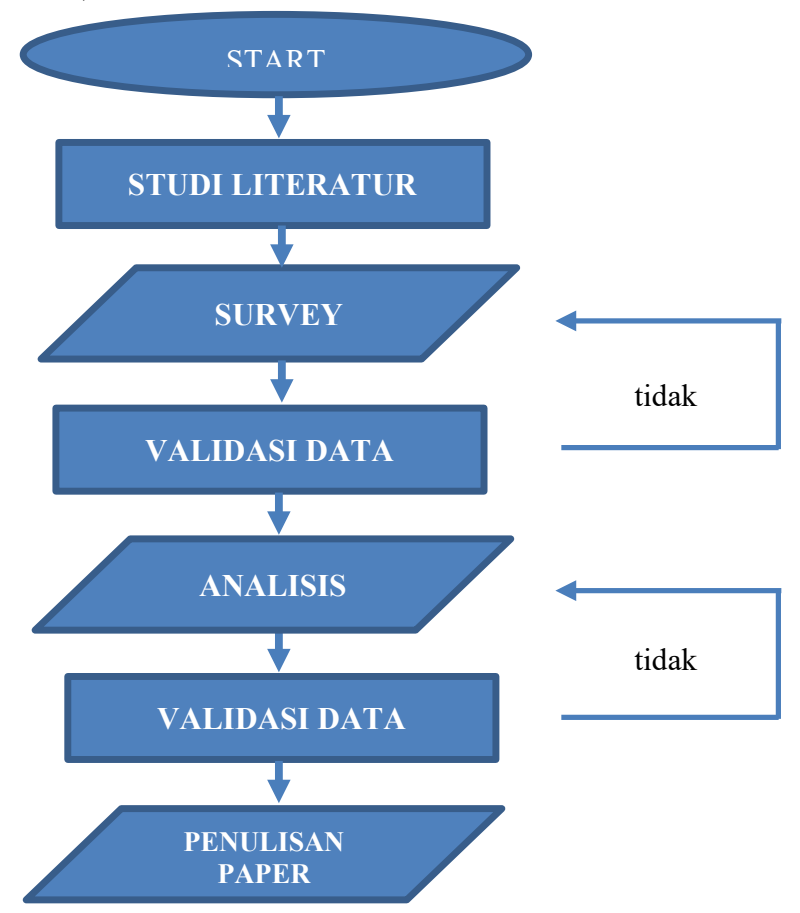




\section{HASIL DAN PEMBAHASAN}

Dalam perbandingan perancangan kali ini dilakukan survey lokasi beban yang ada pada Lab. Listrik PPSDM MIGAS Cepu. Didapatkan tata letak beban dan konsumsi harian beban terpasang pada Lab. Listrik PPSDM MIGAS sebagai berikut :

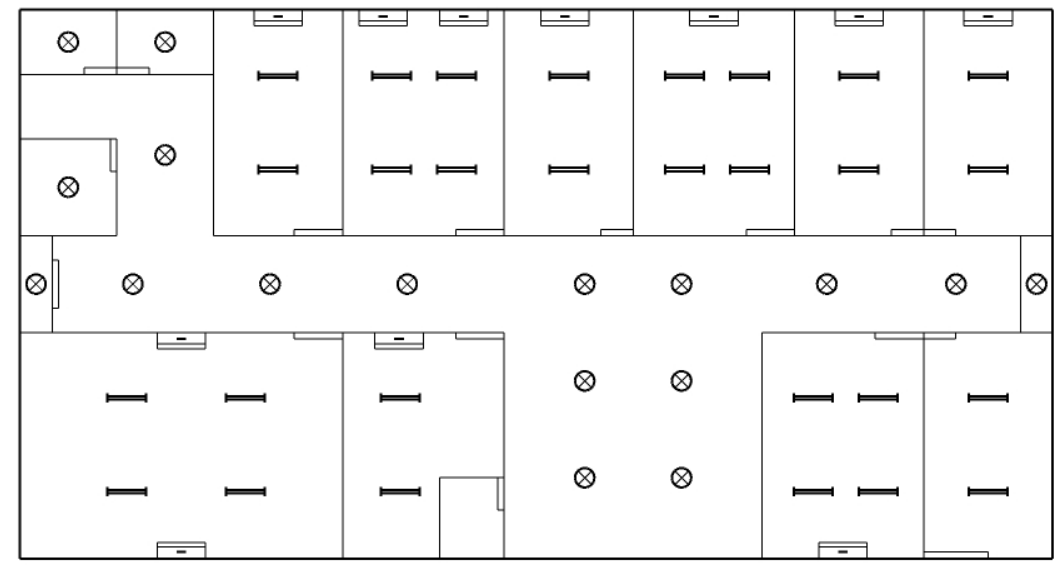

Gambar 1. Tata Letak Beban Lab. Listrik PPSDM MIGAS

Tabel 1. Konsumsi Daya Lisrik Pada Lab. Listrik PPSDM MIGAS

\begin{tabular}{|c|c|c|c|c|c|c|c|}
\hline \multirow[b]{2}{*}{ No } & \multirow[b]{2}{*}{ Peralatan } & \multicolumn{2}{|c|}{ Jumlah Operasi } & \multirow{2}{*}{$\begin{array}{c}\text { Waktu } \\
\text { Operasi } \\
\text { (jam) }\end{array}$} & \multirow{2}{*}{$\begin{array}{c}\text { Daya } \\
\text { Alat } \\
\text { (Watt) }\end{array}$} & \multicolumn{2}{|c|}{ Konsumsi Daya } \\
\hline & & Maksimal & Harian & & & Maks & Harian \\
\hline 1 & Lampu TL 36 & 28 & 0 & 8 & 36 & 8.064 & 0 \\
\hline 2 & $\begin{array}{l}\text { Lampu Bohlam } \\
\text { LED }\end{array}$ & 16 & 2 & 8 & 8 & 1.024 & 128 \\
\hline 3 & Air Conditioner & 10 & 3 & 8 & 860 & 68.800 & 20.640 \\
\hline 4 & $\begin{array}{l}\text { Laptop/Personal } \\
\text { Computer }\end{array}$ & 15 & 4 & 8 & 350 & 42.000 & 10.800 \\
\hline \multicolumn{5}{|c|}{ Total } & 1.254 & 119.888 & 31.568 \\
\hline
\end{tabular}

Konsumsi daya harian tersebut dijadikan sebagai acuan dalam Perbandingan Perancangan PLTS On-Grid dan Off-Grid pada Laboratorium Listrik Pusat Pengembangan Sumber Daya Manusia Minyak dan Gas Bumi.

Untuk keperluan perancangan Pembangkit Listrik Tenaga Surya On-Grid dan Off-Grid pada Laboratorium Listrik Pusat Pengembangan Sumber Daya Manusia Minyak dan Gas Bumi, maka jumlah total konsumsi daya / hari perlu ditambahkan 20\%. Hal itu digunakan untuk sumber daya dari perangkat selain panel surya, yakni inverter sebagai pengubah arus DC (searah) menjadi AC (bolak - balik) (karena pada umumnya peralatan rumah tangga menggunakan arus AC), dan controller (sebagai pengatur arus) yakni menutup arus ke 
baterai jika tegangan sudah berlebih di baterai dan memberhentikan pengambilan arus dari baterai jika baterai sudah hampir kosong. Perhitungannya adalah sebagai berikut :

$$
31.568+(31.568 \times 20 \%)=37.882 \mathrm{Wh} .
$$

Maka total daya terpakai standar perhari menjadi $37.882 \mathrm{Wh}$

\section{Perancangan}

Perancangan PLTS On-Grid dan Off-Grid adalah sebagai berikut :

\section{Panel surya}

Panel surya yang digunakan adalah dengan kapasitas $300 \mathrm{Wp}$ dan asumsi penyinaran matahari 8 jam/hari, sehingga jumlah panel surya yang dibutuhkan:

$$
\text { Total Panel }=\frac{37.882}{300 \times 8}=15,78416667 \text { Panel }
$$

Total Panel $=15,78416667$ Panel $\approx 16$ Panel

\section{Battery Charge Controller}

Battery Charge Controller yang digunakan adalah MPPT 160 Ampere, karena besar nilai Isc (nilai arus maksmum yang dapat dikeluarkan panel surya / Short Circuit Current) pada panel surya adalah 9,64 A sehingga dengan total pemakaian 16 panel surya memerlukan BCR 160 A.

\section{Inverter}

Inverter yang digunakan adalah 5000 Watt XUYUAN $220 \mathrm{~V} 50 \mathrm{~Hz}$ dengan input 12 VDC dan efisiensi $93 \%$.

\section{Baterai}

Baterai yang digunakan 12 Volt 200 Ah. Berdasarkan jenis inverter yang digunakan,inverter akan beroperasi pada tegangan 12 Volt (tegangan input untuk jenis inverter 5000 Watt ). Maka dari ketentuan kebutuhan tegangan input inverter, maka :

Baterai (berdasarkan voltase $)=\frac{12}{12}=1$ pcs baterai (disusun seri)

Panel surya yang digunakan 12 pcs dengan masing - masing $300 \mathrm{Wp}$ dan voltase panel surya adalah 24 Volt, sehingga untuk tiap panel surya membutuhkan baterai :

Baterai (berdasarkan kapasitas) $=\frac{16 \times 300 \mathrm{Wp} \times 24 \mathrm{~V}}{12 \mathrm{~V} \times 200 \mathrm{Ah}}=48$ baterai (disusun paralel)

Sehingga total baterai yang dibutuhkan untuk PLTS adalah 1 x $48=48$ baterai. Besar nilai tegangan input 12 Volt untuk inverter yang digunakan dan jumlah panel surya 16 buah dengan masing - masing $300 \mathrm{Wp}$ serta voltase tiap panel surya 24 Volt inilah yang menyebabkan total baterai yang dibutuhkan untuk PLTS menjadi 48 baterai.

Dari perhitungan diatas didapatkan tabel perbandingan sebagai berikut : 
Tabel 2. Perbandingan Perancangan PLTS

\begin{tabular}{|c|c|c|}
\hline Keterangan & On-Grid & Off-Grid \\
\hline Panel Surya & $\frac{37.882}{300 \times 8}=15,78=16 \mathrm{pcs}$ & $\frac{37.882}{300 \times 8}=15,78=16 \mathrm{pcs}$ \\
\hline $\begin{array}{c}\text { Battery Charge } \\
\text { Controller }\end{array}$ & $1 \mathrm{pcs}(160 \mathrm{~A})$ & $1 \mathrm{pcs}(160 \mathrm{~A})$ \\
\hline Inverter & $1 \mathrm{pcs}(5000 \mathrm{Watt} 220 \mathrm{~V} 50 \mathrm{~Hz})$ & $1 \mathrm{pcs}(5000 \mathrm{Watt} 220 \mathrm{~V} 50 \mathrm{~Hz})$ \\
\hline Baterai & $0 \mathrm{pcs}$ & $48 \mathrm{pcs}$ \\
\hline
\end{tabular}

\section{Perhitungan Perancangan}

Tabel 3. Perbandingan Biaya Peralatan dan Pemasangan PLTS

\begin{tabular}{|c|l|c|c|c|c|c|}
\hline \multirow{2}{*}{ No } & \multicolumn{1}{|c|}{$\begin{array}{c}\text { Peralatan dan } \\
\text { Spesifikasi }\end{array}$} & \multicolumn{1}{c|}{$\begin{array}{c}\text { Harga } \\
(\mathrm{Rp})\end{array}$} & \multicolumn{2}{|c|}{ Jumlah (Pcs) } & \multicolumn{2}{|c|}{ Jumlah (Rp) } \\
\cline { 5 - 7 } 1 & $\begin{array}{l}\text { Panel Surya 300 } \\
\text { Wp }\end{array}$ & 3.600 .000 & 16 & 16 & 57.600 .000 & 57.600 .000 \\
\hline 2 & $\begin{array}{l}\text { Baterai VRLA } \\
\text { Roket 12V 200 } \\
\text { Ah }\end{array}$ & 2.000 .000 & 0 & 48 & 0 & 96.000 .000 \\
\hline 4 & $\begin{array}{l}\text { BCR MPPT } \\
160 A\end{array}$ & 1.000 .000 & 1 & 1 & 1.000 .000 & 1.000 .000 \\
\hline 5 & $\begin{array}{l}\text { Inverter 5000 W } \\
12 \text { V XUYUAN }\end{array}$ & 560.000 & 1 & 1 & 560.000 & 560.000 \\
\hline 6 & $\begin{array}{l}\text { Rak Panel Surya } \\
+ \text { Wiring/panel }\end{array}$ & 100.000 & 16 & 16 & 1.600 .000 & 1.600 .000 \\
\hline 7 & Rak Baterai & 100.000 & 0 & 48 & 0 & 4.800 .000 \\
\hline 8 & $\begin{array}{l}\text { Biaya } \\
\text { Pemasangan dan } \\
\text { Ongkos Kerja }\end{array}$ & $1.500 .000 /$ & $4.800 \mathrm{~W}$ & $4.800 \mathrm{~W}$ & 7.200 .000 & 7.200 .000 \\
\hline
\end{tabular}

Untuk biaya pemasangan dan upah pekerja dihitung tiap pemasangan $1000 \mathrm{~W}$, akan dikenakan biaya Rp. 1.500.000 yang diperoleh dari PT. ET Tedeon di Glodok Jakarta Pusat. 
Untuk PLTS ini menggunakan 16 panel surya dengan masing - masing $300 \mathrm{Wp}$, sehingga untuk PLTS ini dengan 16 x 300 Watt $=4800 \mathrm{~W}$ dikenakan biaya Rp.7.200.000.

\section{Perhitungan Perancangan dan Operasional 25 Tahun}

Biaya baterai yang didapat dari PT. ET Tedeon di Glodok, Jakarta Pusat, terjadi 4 kali pergantian baterai selama 25 tahun karena tiap baterai memiliki umur pakai hanya selama 5 tahun dan untuk menghitung analisa ekonomis dari PLTS selama 25 tahun maka biaya baterai pun perlu dikali 4 .

0

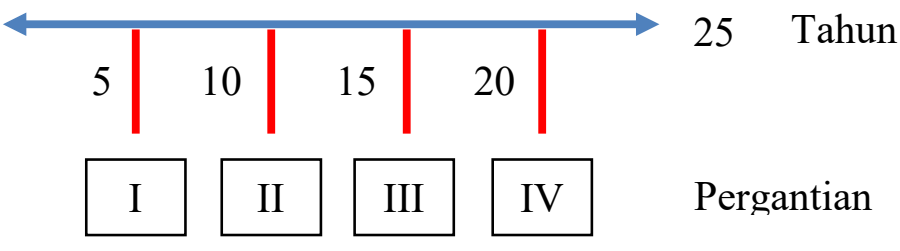

Gambar 2. Jumlah Pergantian Baterai Selama 25 Tahun

Berdasarkan informasi dari PT. ET Tedeon di Glodok, Jakarta Pusat. Dari seluruh komponen PLTS yang digunakan, peningkatan harga tiap tahun dimiliki oleh baterai selama 25 tahun, namun tidak dapat dipastikan berapa besar peningkatan harga baterai tersebut karena banyak faktor yang tidak pasti seperti perubahan kurs rupiah, inflasi, sistem pemerintahan, perubahan harga minyak dunia. Sehingga harga baterai 12 Volt 200 Ah diasumsikan tetap Rp.2.000.000/pc selama 25 tahun. Sehingga untuk penambahan total biaya operasional selama 25 tahun hanya untuk pergantian baterai adalah:

$$
\begin{array}{ll}
\text { Biaya Operasional } & =\text { Pergantian } \times \text { Harga Barang (baterai) } \\
& =4 \times \text { Rp. } 96.000 .000 \\
& =\text { Rp. } 384.000 .000
\end{array}
$$

Karena terdapat penambahan biaya operasional dalam perancangan PLTS. Maka perhitungan biaya perancangan dalam kurun waktu 25 tahun adalah sebagai berikut :

$$
\begin{aligned}
\text { Biaya PLTS On-Grid } \quad & =\text { Biaya Perancangan }+ \text { Biaya Operasional } \\
& =\text { Rp. } 67.960 .000+\text { Rp. } 0 \\
& =\text { Rp. } 67.960 .000 \\
\text { Biaya PLTS Off-Grid } \quad & =\text { Biaya Perancangan + Biaya Operasional } \\
& =\text { Rp. } 168.760 .000+\text { Rp. } 384.000 .000 \\
& =\text { Rp. } 552.760 .000
\end{aligned}
$$


Biaya Listrik PLN

$$
\begin{aligned}
& =\text { Rp. } 1.035,78 \times 365 \times 25 \\
& =\text { Rp. } 358 \cdot 041.438,9
\end{aligned}
$$

Tabel 4. Perbandingan Biaya Operasional PLTS

\begin{tabular}{|c|c|c|c|}
\hline \multirow{2}{*}{ Keterangan } & \multicolumn{3}{|c|}{ Biaya (Rupiah) } \\
\cline { 2 - 4 } & On-Grid & Off-Grid & Listrik PLN \\
\hline Operasional 25 Tahun & 67.960 .000 & 552.760 .000 & 358.041 .439 \\
\hline Operasional 1 Tahun & 2.718 .400 & 22.110 .400 & 14.321 .658 \\
\hline Operasional 1 Hari & 7.447 & 60.576 & $39.237,41$ \\
\hline
\end{tabular}

Pada tabel diatas menggunakan acuan 1 tahun $=365$ hari, dan biaya operasional serta perawatan lain diabaikan. Sehingga pada PLTS On-Grid dalam kurun waktu 25 tahun sama sekali tidak memerlukan biaya operasional dan perbaikan dalam pelaksanaan-nya, dan pada PLTS Off-Grid hanya melakukan pergantain baterai saja. Untuk acuan harga listrik PLN adalah Rp. 1.035,78 sesuai dengan harga listrik PLN P-2/TR >200kV.

Dari tabel diatas didapatkan bahwa yang memiliki tingkat biaya perancangan dan operasional terendah adalah perancangan PLTS On-Grid. Dikarenakan pada perancangan PLTS On-Grid tidak memerlukan biaya pergantian baterai seperti PLTS Off-Grid. Sehingga PLTS On-Grid memiliki tingkat harga yang jauh lebih rendah. Tetapi dalam pelaksanaannya PLTS On-Grid masih memerlukan listrik PLN jika sewaktu-waktu cuaca tidak mendukung (mendung). Sebaliknya, pada PLTS Off-Grid memiliki biaya yang cukup mahal. Tetapi dalam pelaksanaannya PLTS Off-Grid tidak memerlukan listrik PLN jika cuaca tidak mendukung, karena PLTS Off-Grid memiliki baterai yang bisa digunakan ketika cuaca tidak mendukung.

\section{KESIMPULAN}

Pada perancangan PLTS Off-Grid kali ini menggunakan panel surya $300 \mathrm{Wp}$ sebanyak 16 pcs, baterai 12 V 200 Ah sebanyak 48 pcs, inverter 12V/24V 5000 Watt 1 pc, dan BCR MPPT 160 A 1 pc. Sedangkan pada perancangan PLTS On-Grid sama seperti PLTS OffGrid, hanya saja pada perancangan PLTS On-Grid tidak menggunakan baterai. Biaya perancangan dan operasional dalam kurun waktu 1 hari adalah sebagai berikut :

$$
\begin{array}{ll}
\text { Biaya PLTS On-Grid } & =\text { Rp. } 7.447 \\
\text { Biaya PLTS Off-Grid } & =\text { Rp. } 60.576
\end{array}
$$


Biaya Listrik PLN $=$ Rp. 39.237

Dapat ditarik kesimpulan bahwa dalam perancangan kali ini PLTS On-Grid memiliki tingkat efisiensi terbaik dalam segi biaya perancangan dan operasional. Namun, dalam pelaksanaannya PLTS On-Grid masih membutuhkan listrik PLN sewaktu-waktu jika cuaca tidak mendukung.

Untuk penelitian selanjutnya dapat dilakukan perbandingan Pembangkit Listrik Tenaga Surya dengan Pembangkit Listrik Tenaga Hybrid. Sehingga dapat menemukan komposisi yang pas dalam melakukan perancangan pembangkit listrik dengan efisiensi harga dan kebersihan lingkungan yang maksimal.

\section{DAFTAR PUSTAKA}

Anonim. 2016. Biaya komponen dan peralatan PLTS. Jakarta : PT. ET Tedeon.

Badan Pusat Statistika (2017). Suvey Tahunan Migas Dari Tahun ke Tahun. Retrieved from https://www.bps.go.id/

Bukalapak.com. (2020). Panel Surya, Baterai, Inverter, BCR. Retrieved from https://www.bukalapak.com/

Lazada.co.id. (2020). Panel Surya, Baterai, Inverter, BCR. Retrieved from https://www.lazada.co.id/

Peter Gevorkian Ph.D.,P.E., "Solar Power System Physics And Technologies" Alternative Energy Systems in Building Design, The McGraw Hill Companies, 2010, hal 143 - 145.

Sandro Putra dkk, 2014, Perencanaan Pembangkit Listrik Tenaga Surya Secara Mandiri Untuk Rumah Tinggal, prosiding SNC 2016, ISSN 2540-7589.

Shopee.co.id. (2020). Panel Surya, Baterai, Inverter, BCR. Retrieved from https://www.shopee.co.id/

SollarCellSurya.com. (2020). Jenis-jenis Panel Surya. Retrieved from https://www.solarcellsurya.com/jenis-panel-surya

W.Shepherd, D.W.Shepherd. Energy Studies Imperial College Press Second Edition 2002; Chap 3:90-92. 